\title{
Comparative efficacy of bilastine, levocetirizine and desloratadine updosing in chronic urticaria
}

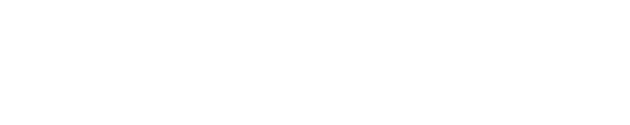

\section{Maria T Staevska}

Clinical Center of Allergology, Medical University, Sofia, Bulgaria
Correspondence: Maria T Staevska Clinical Centre of Allergology, Medical University Sofia, I St George Sofiiski Blvd, Sofia I43I, Bulgaria

Email mari66sta@gmail.com

\section{Dear editor}

As a group of allergists who treat both allergic rhinitis and urticaria patients on a daily basis, and involved in clinical research, we read with particular interest the review paper "Treatment of allergic rhinitis and urticaria: a review of the newest antihistamine drug bilastine", ${ }^{1}$ published in your journal. Although the group of distinguished authors from the Asia Pacific Region provide an interesting insight into the burden of allergic diseases in this fast developing part of the world, no new data or insights are offered for the treatment of these diseases. Our attention was particularly drawn by Figure 9, which is partly based on data generated in a clinical study performed and published by our group. ${ }^{2}$

We would like to take this opportunity to bring some clarifications that we consider important for the readers.

It is regrettable that Figure 9 wrongly presents our results, which is compounded by the fact that it compares data from studies having completely different designs and objectives. According to this figure, desloratadine has a higher response rate of $27.1 \%$, when used at doses of $20 \mathrm{mg}$ once daily, than levocetirizine's response rate of $21.7 \%$ : a misrepresentation of our results. According to Figure 2 of our primary publication, ${ }^{2}$ 12 patients (around 30\%) became symptom-free (responders) when treated with levocetirizine $20 \mathrm{mg}$ and only 1 patient $(<3 \%)$ became symptom-free when treated with desloratadine $20 \mathrm{mg}$. In fact, 7 of the patients who responded to levocetirizine $20 \mathrm{mg}$ were nonresponders to desloratadine $20 \mathrm{mg}$. In addition, Figure 9 seems to indicate that the number of the desloratadine-treated patients in our study was more than twice as large as the levocetirizine-treated patients ( 59 vs 23 , respectively), which is also incorrect. The treatment groups in our study were well-balanced, with 40 patients in each group at randomization.

As Figure 2 of our primary publication may have been challenging for some, we would like to offer a different presentation of our data (Figure 1).

In addition to what appears to be incorrect presentation of our data, we consider the comparison of data in the same graph from completely different studies to be questionable. The desloratadine and levocetirizine data come from our study, ${ }^{2}$ whereas the bilastine data come from Krause et al. ${ }^{3}$ Our study was a clinical trial in difficult-to-treat chronic urticaria patients who were initially treated with the recommended doses of desloratadine $5 \mathrm{mg}$ and levocetirizine $5 \mathrm{mg}$, and only those patients who were not symptom-free after the first study week were put on increasing doses of the study medications. The study by Krause et $\mathrm{al}^{3}$ recruited patients with cold contact urticaria whose symptoms were 


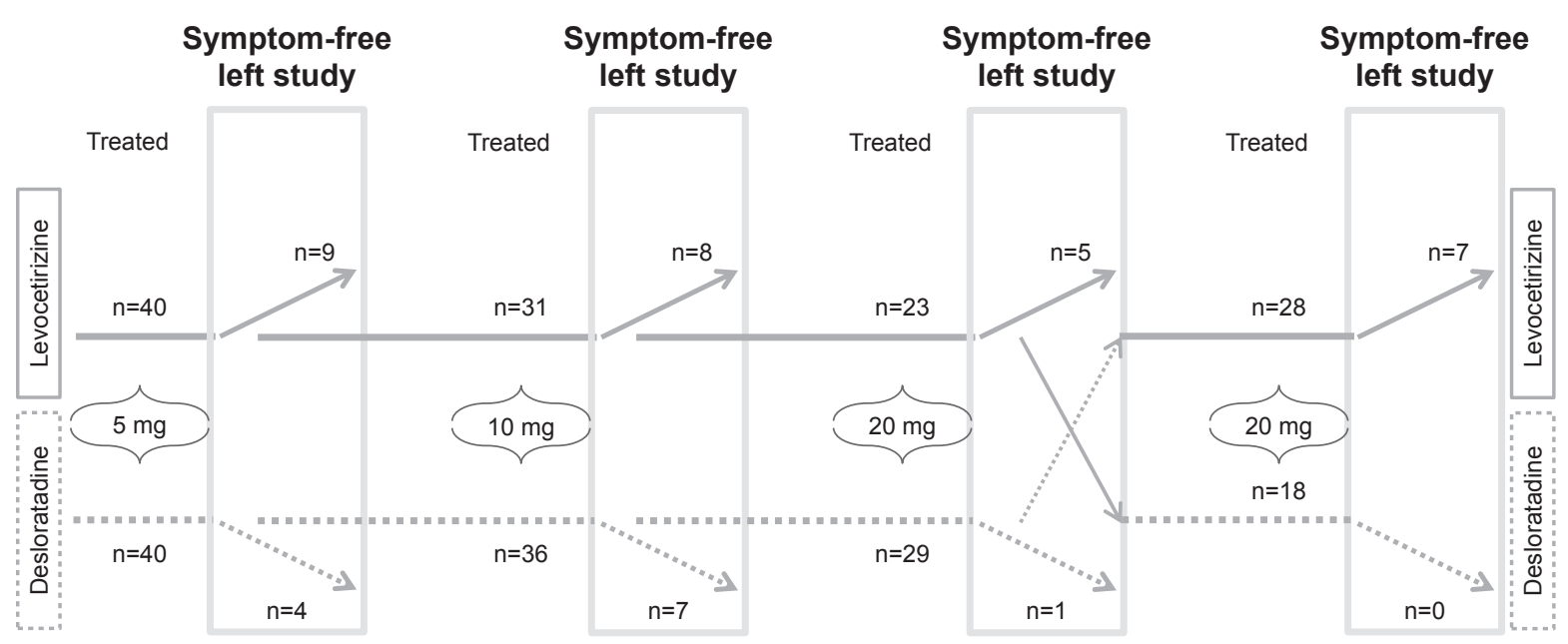

Figure I The study design with the treatment arms and the crossover step.

Notes: The symptom free patients left the study and the rest went on the higher dose. The final group of symptomatic patients went to the crossover step.

elicited by a cold provocation test, and they all received, in a crossover manner, 20,40, or $80 \mathrm{mg}$ bilastine over 1 week. Thus, the subjects in the bilastine study had a different disease, their symptoms were artificially elicited, and they were not treated with sequentially increasing antihistamine doses. Moreover, the $60 \%$ responder rate for $80 \mathrm{mg}$ bilastine was not obtained in nonresponders to $20 \mathrm{and} / \mathrm{or} 40 \mathrm{mg}$ of this drug. To make data more comparable with this study, we can calculate the cumulative responder rate in our study on difficult-totreat chronic urticaria that is $43 \%$ for levocetirizine group (29 symptom-free patients from 68 patients: 40 patients entering the study on levocetirizine plus 28 desloratadine nonresponsive patients eventually treated with $20 \mathrm{mg}$ levocetirizine) versus $21 \%$ for desloratadine group (12 symptom-free patients from 58 patients: 40 patients entering the study on desloratadine plus 18 levocetirizine nonresponsive patients eventually treated with $20 \mathrm{mg}$ desloratadine). These findings support our clinical observations demonstrating similar efficacy for levocetirizine and bilastine and that both are superior in efficacy compared to desloratadine.

It is also regrettable that our data were used to generate Figure 9 without any reference to our primary publication, which does not even appear in the list of references. Instead, this review paper used yet another review ${ }^{4}$ as a reference.

In conclusion, we would like to emphasize that bilastine is a very valuable and efficacious option for many patients treated in our clinic and we welcome any new medications that could help us to effectively deal with the increasing severity and prevalence of modern allergies.

\section{Disclosure}

The author reports no conflicts of interest in this communication.

\section{References}

1. Wang XY, Lim-Jurado M, Prepageran N, Tantilipikorn P, Wangde Y. Treatment of allergic rhinitis and urticaria: a review of the newest antihistamine drug bilastine. Ther Clin Risk Manag. 2016;12:585-597.

2. Staevska M, Popov TA, Kralimarkova T, et al. The effectiveness of levocetirizine and desloratadine in upto 4 times conventional doses in difficultto-treat urticaria. J Allergy Clin Immunol. 2010;125(3):676-682.

3. Krause K, Spohr A, Zuberbier T, Church MK, Maurer M. Up-dosing with bilastine results in improved effectiveness in cold contact urticaria. Allergy. 2013;68(7):921-928.

4. Sánchez-Borges M, AnsoteguiI, Jimenez JM, Rojo MI, Serrano C, Yañez A. Comparative efficacy of non-sedating antihistamine updosing in patients with chronicurticaria. World Allergy Organ J. 2014;7:33. 


\section{Author's reply \\ De Yun Wang}

Department of Otolaryngology, Yong Loo Lin School of Medicine, National University of Singapore, Singapore

Correspondence: De Yun Wang

Department of Otolaryngology, Yong Loo Lin School of Medicine,

National University of Singapore, IE Kent Ridge Road, Singapore I I 9228

Tel +6567725373

Fax +65 67753820

Email entwdy@nus.edu.sg

\section{Dear editor}

Thank you for the opportunity to review the content of the letter by Staevska in response to our article entitled Treatment of allergic rhinitis and urticaria: a review of the newest antihistamine drug bilastine. ${ }^{1}$

The objective of this article has been to review the current burden of allergic rhinitis and urticaria in the Asia Pacific region, to briefly describe the evolution of antihistamine pharmacology, and to systematically review the pharmacological characteristics and clinical results of bilastine, a new antihistamine that is highly selective for the $\mathrm{H} 1$ histamine receptor.

Figure 9 in our article presents data from an indirect comparison of data from several clinical trials (including the one by Staevska et $\mathrm{al}^{2}$ ) published in World Allergy Organization Journal. ${ }^{3}$ It is described thus in our paper "A comparison of clinical trial data for second-generation antihistamines in chronic urticaria suggests that this bilastine dosage is significantly more effective than supratherapeutic dosages of desloratadine and levocetirizine (Figure 9)." The data presented in Figure 9 are as they appear in the indirect comparison paper by Sánchez-Borges et al. ${ }^{3}$ In our opinion, should there be any criticism of the interpretation of these data, it should be leveled at the authors of the indirect comparison (SánchezBorges et al), yet we were unable to find any correspondence indicating that this has taken place.

A couple of things to note about our use of these data:

- Because our article was focused on bilastine, the Staevska et $\mathrm{al}^{2}$ article, which includes desloratidine and levocetirizine, was not captured by the original literature search but the Sánchez-Borges paper was.

- The Sánchez-Borges paper is labeled by the journal that published it as "original research," presumably because they applied comparative analysis to previously published data.

- Although we could have sourced the original paper, as suggested by Staevska in this letter, to verify the findings of the Sánchez-Borges analysis, we had no reason to suspect that the Sánchez-Borges analysis misrepresented the original findings, and our description of the analysis (as a comparison of clinical trial data) does not overstate the Sánchez-Borges conclusions.

- The Staevska et $\mathrm{al}^{2}$ study, which used a dose-escalation protocol, may have achieved a higher cumulative response rate with levocetirizine (43\%) and desloratidine (21\%) than has been represented in the Sánchez-Borges paper, but this rate is still numerically lower than the $60 \%$ response rate to bilastine described in the paper by Krause et al. ${ }^{4}$ Therefore, our statement that the analysis suggests a higher response rate with bilastine than levocetrizine is not inaccurate.

- The patient number of $\mathrm{n}=59$ for desloratidine $20 \mathrm{mg}$ once daily in the figure is correct because this portion of the graph includes combined data from the Staevska et $\mathrm{al}^{2}$ paper and one by Siebenhaar et al. ${ }^{5}$ This fact may have escaped the letter's authors. If they thought that the desloratidine portion of the graph contained only data from their own paper, it is little wonder that the graph seemed to misrepresent the findings of their 2010 study.

Arguably, Sánchez-Borges et al should not have included the Staevska et al $^{2}$ study in their indirect comparison of highdose antihistamines, as the Staevska et al study did not use a fixed dose of drug (in both arms, the dose was escalated to achieve maximal benefit and patients who did not respond to the maximal dose of one agent were switched to the other). Similarly, the authors may have a point that the bilastine study, in which patients with cold urticaria underwent cold challenge, should not have been compared alongside the others in the Sánchez-Borges analysis. Nevertheless, cold urticaria is a form of chronic urticaria and we repeat our contention that we have not overstated or misrepresented the data presented by Sánchez-Borges et al.

Naturally, we fully support the principles of open scientific debate, if this is accomplished through substantiated and science-driven observations together with full understanding of the article these remarks are destined to.

\section{Disclosure}

The author reports no conflicts of interest in this communication.

\section{References}

1. Wang XY, Lim-Jurado M, Prepageran N, Tantilipikorn P, Wangde Y. Treatment of allergic rhinitis and urticaria: a review of the newest antihistamine drug bilastine. Ther Clin Risk Manag. 2016;12:585-597.

2. Staevska M, Popov TA, Kralimarkova T, et al. The effectiveness of levocetirizine and desloratadine in upto 4 times conventional doses in difficultto-treat urticaria. J Allergy Clin Immunol. 2010;125(3):676-682. 
3. Sánchez-Borges M, AnsoteguiI, Jimenez JM, Rojo MI, Serrano C, Yañez A. Comparative efficacy of non-sedating antihistamine updosing in patients with chronicurticaria. World Allergy Organ J. 2014;7:33.

4. Krause K, Spohr A, Zuberbier T, Church MK, Maurer M. Up-dosing with bilastine results in improved effectiveness in cold contact urticaria. Allergy. 2013;68(7):921-928.
5. Siebenhaar F, Degener F, Zuberbier T, Martus P, Maurer M. High-dose desloratadine decreases wheal volume and improves cold provocation thresholds compared with standard-dose treatment in patients with acquired cold urticaria: a randomized, placebo-controlled, crossover study. J Allergy Clin Immunol. 2009;123(3):672-679.

Dove Medical Press encourages responsible, free and frank academic debate. The content of the Therapeutics and Clinical Risk Management 'letters to the editor' section does not necessarily represent the views of Dove Medical Press, its officers, agents, employees, related entities or the Therapeutics and Clinical Risk Management editors. While all reasonable steps have been taken to confirm the content of each letter, Dove Medical Press accepts no liability in respect of the content of any letter, nor is it responsible for the content and accuracy of any letter to the editor.

\section{Publish your work in this journal}

Therapeutics and Clinical Risk Management is an international, peerreviewed journal of clinical therapeutics and risk management, focusing on concise rapid reporting of clinical studies in all therapeutic areas, outcomes, safety, and programs for the effective, safe, and sustained use of medicines. This journal is indexed on PubMed Central, CAS,
EMBase, Scopus and the Elsevier Bibliographic databases. The manuscript management system is completely online and includes a very quick and fair peer-review system, which is all easy to use. Visit http://www.dovepress.com/testimonials.php to read real quotes from published authors.

Submit your manuscript here: http://www.dovepress.com/therapeutics-and-clinical-risk-management-journal 